\title{
Measuring the ups and downs of pregnancy stress
}

\author{
J. A. DiPietro, M. M. Ghera, K. Costigan and \\ M. Hawkins
}

Despite substantial interest in the effects of stress on pregnancy, few instruments are available to measure pregnancy-specific stressors. Moreover, research has typically focused on the distressing, negative aspects of pregnancy. This report examines the reliability and validity of the Pregnancy Experience Scale (PES), a 41 item scale that measures pregnancy-specific daily hassles and uplifts. The PES was administered to two cohorts of low risk women at 24, 30, and 36 weeks $(n=52)$ or 32 and 38 weeks $(n=137)$. Women perceived their pregnancies to be significantly more intensely and frequently uplifting than hassling. Internal scale reliability was high ( $\alpha=0.91$ to 0.95). Frequency and intensity scores for hassles and uplifts were stable over time ( $r$ 's $=0.56$ to 0.83 ) and patterns of convergent and discriminant validity emerged between the PES and existing measures of general affective intensity, daily stressors, depressive symptoms, and anxiety. These results indicate that (1) failure to measure pregnancy-specific stress will underestimate the degree to which pregnant women experience distress and (2) measurement of only the negative aspects of pregnancy will overestimate distress and fail to portray the degree to which women are psychologically elevated by their pregnancies. Measurement of hassles relative to uplifts may provide the most balanced assessment of pregnancy appraisal.

Key words: pregnancy, pregnancy stress, uplifts, hassles

'For behold, the moment that the sound of thy greeting came to my ears, the babe in my womb leapt for joy.' Luke 1:44.

The notion that maternal emotions affect the developing fetus has been promulgated since biblical times. A convergent body of academic evidence supports maternal psychosocial factors as contributors to fetal development and pregnancy outcomes. Negative emotions, including maternal anxiety and perceived stress, are associated with reduced fetal heart rate variability ${ }^{1}$, greater motor activity ${ }^{2,3}$, alterations in state ${ }^{4,5}$, and disturbances to fetal habituation ${ }^{6}$. Affected outcomes include spontaneous abortions ${ }^{7,8}$, pregnancy complications ${ }^{9}$, shortened length of gestation, preterm delivery and/or low birth weight ${ }^{10-17}$. Several comprehensive re- views detail these associations ${ }^{18-21}$. There is a smaller, but growing, body of evidence linking antenatal stress to more distal outcomes, including cognitive and behavioral functioning ${ }^{22-24}$. Although psychosocial stress may predispose pregnant women to adopt less healthy behaviors, mediation of stress effects has been linked most strongly to disruption of the hypothalamic-pituitaryadrenal axis during pregnancy ${ }^{25-28}$.

The construct of stress is notoriously difficult to operationalize. Stress research during pregnancy has been hampered by the methodological issues common to stress studies in general ${ }^{29,30}$. These include the use of measurement tools in populations on which they were not validated, the role of appraisal in judging events, and imprecision in distinguishing the construct of stress from
*J. A. DiPietro, M.

Hawkins, Department of Population and Family Health Sciences, Johns Hopkins University, Baltimore, MD, USA, M. M. Ghera, Department of Human Development, University of Maryland, College Park, MD, USA, and K. Costigan, Division of Maternal-Fetal Medicine, Johns Hopkins University, Baltimore, MD, USA

* Correspondence to: Janet DiPietro, Department of Population and Family Health Sciences, Johns Hopkins University, 615 N. Wolfe St., E4531, Baltimore, MD 21205, USA. Email: jdipietr@jhsph.edu 
that of aspects of emotionality, particularly trait anxiety. Evaluating stress during pregnancy raises additional methodological issues including confounds introduced by medical or social risk factors that may covary with psychological distress. In particular, the number of children and/or previous pregnancies a woman has had may differentially affect physiological and psychosocial responses to the current pregnancy. Ascertaining the timing of stress exposure in relation to the start of pregnancy and stage of gestation provides further challenge in detecting significant associations ${ }^{29}$.

A relatively unrecognized methodological issue in measuring stress during pregnancy is that pregnancy itself presents unique psychological and social challenges ${ }^{31-33}$; thus failure to measure pregnancy-specific sources can underestimate maternal distress. Pregnancy-specific measures have not been commonly included in studies on birth outcomes, but efforts to develop such scales have identified a wide range of concerns unique to pregnant women ${ }^{9,34-36}$. Some scales were designed to be used only with low income or high risk populations ${ }^{37,38}$; others have focused on pregnancy-related anxiety ${ }^{39}$.

Measurement of daily, minor challenges has become an established method of capturing the daily hassles of life $\mathrm{e}^{40,41}$. Measurement of hassles that are not pregnancyspecific has been incorporated into studies of pregnancy,23,42-44 and the postpartum ${ }^{45}$. However, these scales have been reported to be simultaneously over-representative in containing hassles rarely experienced by pregnant women but under-representative because of their lack of pregnancy-specific concerns $^{46}$.

Equally at issue is the emphasis on pregnancy as a stressful, anxiety-provoking event, despite our cultural perception of pregnancy as time of joy and contentment. Recently, such positive emotions have secured a more visible role in understanding the role of psychosocial factors in health ${ }^{47-49}$. Consistent with this orientation, an optimistic disposition has been shown to buffer against both emotional distress and negative pregnancy outcomes ${ }^{50}$. Although the original daily stress scales included uplifts as well as hassles ${ }^{41}$, most reports focus on hassles and do not disseminate (or, perhaps, collect) uplifts data. There is one report on fluctuations in non-pregnancy hassles and uplifts during pregnancy, which indicates that advancing gestation is associated with great- er intensity of hassles and reduced intensity of uplifts ${ }^{44}$.

The pregnancy specific scale used in the present study was designed to measure both the hassles and uplifts that are generated by the pregnancy. A recent report of the relationship between this scale and fetal functioning revealed the following: fetuses of women who reported a greater number of pregnancy hassles moved more and had marginally faster heart rate in the second half of pregnancy, and higher heart rate variability near term ${ }^{2}$. In contrast, women reporting feeling more uplifted about their pregnancy (both in terms of greater intensity and higher number of uplifts) had fetuses who were significantly less active. Pregnancy specific measures were more robustly related to fetal behavior than either non-pregnancy specific stressors or affect. Because the fetus reacts to maternal physiological signals, the results of that study suggest that the pregnancy experience scale used provides information about aspects of the psychological experience of pregnancy that influence maternal physiologic arousal. Having established its validity in this manner, the goal of the current report is to document the psychometric properties of this scale and examine convergent and discriminant validity with other psychosocial measures in two samples of pregnant women during the second half of gestation.

\section{METHODS}

\section{Participants}

Participants were 189 healthy women with low risk pregnancies who took part in one of two longitudinal studies of fetal neurobehavioral development ( $n \mathrm{~s}=52$ and 137). Enrollment was restricted to women with singleton pregnancies who were non-smokers, non-drug users, and had no significant medical or pregnancy risk factors. Subjects who developed pregnancy conditions (e.g., gestational diabetes, preterm labor or delivery, etc) or delivered infants with undetected conditions of fetal origin (e.g., growth retardation) were excluded from this final sample. All participants were self-referred volunteers. Gestational age ascertainment was based on a pregnancy test within one month of the last missed menstrual period, a first trimester obstetric or ultrasound examination, or both. Maternal characteristics for each cohort are presented in Table 1. Women in Cohort 2 were slightly older $(t(187)=2.11$, 
Table 1 Maternal characteristics

\begin{tabular}{lcc}
\hline & $\begin{array}{c}\text { Cohort 1 } \\
(\mathrm{n}=52)\end{array}$ & $\begin{array}{c}\text { Cohort 2 } \\
(\mathrm{n}=137)\end{array}$ \\
\hline Maternal age & 29.9 & 31.3 \\
SD & $(3.5)$ & $(4.1)$ \\
Maternal education (years) & 16.3 & 16.7 \\
SD & $(2.6)$ & $(2.1)$ \\
High School & $14 \%$ & $5 \%$ \\
$<4$ years college & $15 \%$ & $16 \%$ \\
College degree & $25 \%$ & $34 \%$ \\
Graduate training & $46 \%$ & $45 \%$ \\
Married & $94 \%$ & $94 \%$ \\
Nulliparous & $63 \%$ & $55 \%$ \\
Race & & \\
$\quad$ White & $77 \%$ & $85 \%$ \\
African-American & $10 \%$ & $12 \%$ \\
Asian & $13 \%$ & $3 \%$ \\
\hline
\end{tabular}

$p<0.05)$ but did not differ on other sociodemographic characteristics. Both samples represent well-educated, employed women at low risk for poor pregnancy outcomes.

\section{Study design}

The design of the parent studies focused on the longitudinal relationship between fetal neurobehavioral development and maternal psychosocial functioning. Women in Study 1 (hereafter, Cohort 1, $n=52$ ) completed the same three psychosocial assessments at 24, 30 , and 36 weeks gestation. Study 2 (Cohort 2; $n=137)$ included six data collection visits beginning at 20 weeks gestation. The research was approved by the Institutional Review Board and all women provided informed consent. The pregnancy-specific scale that is the focus of this report was administered to women in both cohorts. The study comprised of Cohort 1 was designed to allow longitudinal modeling at three points in gestation by using identical psychosocial measures at each assessment. Results linking psychological stress and fetal behavior have been presented elsewhere ${ }^{2}$. The protocol involving Cohort 2 included a greater number of subjects sampled at twice as many assessment points. In order to examine a broader array of psychosocial features in relation to fetal functioning than had been measured in Cohort 1 and to reduce participant burden, scales assessing additional constructs (e.g., anxiety, depression) were administered at different times during gestation. Psychosocial data from Cohort 2 has not been presented elsewhere. Inclusion of both cohorts in the current report has the following advantages: a larger sample size for item analysis; extension into full-term gestation by Cohort 2; an opportunity to evaluate patterns of change over pregnancy and potential parity effects over different gestational periods; and replication of test-retest reliability and validation with stress and affect scales administered to both cohorts. Table 2 presents the schedule of psychosocial scale administration in each cohort.

\section{Psychosocial assessments}

Pregnancy Experience Scale (PES). This scale was developed to measure maternal appraisal of exposures to daily, ongoing hassles and uplifts that are specific to pregnancy (e.g., 'Discussing baby names with your spouse,' 'Making nursery arrangements,' 'Physical symptoms'). The PES structure was modeled on the non-pregnancy Hassles and Uplifts Scale $^{41}$. Items were generated by non-directive interviews of 31 pregnant, middle-class women who were participants in a previous study in which the only measure of stress was not specific to pregnancy ${ }^{1}$. A total of 50 items were generated; 41 -items were retained that had face validity and minimized overlap. However, some items with partial redundancy were retained if they were nominated frequently or intensely. For example, family and in-law issues, when experienced, generated high levels of hassle intensity across a spectrum of issues. Respondents are directed to indicate whether each item is appraised as either a hassle and/ or an uplift on a 4-point Likert scale ranging from 0 (not at all) to 3 (a great deal). The scale is included in the Appendix.

Scoring included computation of the frequency (number of endorsed items) as well as the intensity (i.e., sum of scores divided by the number of endorsed items) of endorsed hassles and uplifts. The rationale for computing both dimensions has been well supported ${ }^{51}$. Additionally, a composite ratio score relating hassles to uplifts (i.e., frequency hassles divided by frequency uplifts) for both frequency and intensity scale scores was computed to ascertain positive versus negative valence towards pregnancy. Values greater than 1 indicate more hassles than uplifts; scores lower than 1 indicate more uplifts than hassles.

Daily Stress Inventory (DSI) ${ }^{52}$ assesses nonpregnancy specific stressors. The DSI lists 58 events (e.g., 'Spoke in public,' 'Had car trouble') which are scored on a 7-point scale of stressfulness. Events that have occurred 
Table 2 Schedule of administration of psychosocial measures by gestational age in weeks

\begin{tabular}{lcc}
\hline Measure & Cohort $1(\mathrm{n}=52)$ & Cohort $2(\mathrm{n}=137)$ \\
\hline Pregnancy Experience Scale (PES) & $24,30,36$ & 32,38 \\
Daily Stress Inventory (DSI) & $24,30,36$ & 36 \\
Affective Intensity Measure (AIM) & $24,30,36$ & 36 \\
Depressive symptoms (CESD) & - & 32 \\
Trait Anxiety (STAI) & - & 28 \\
\hline
\end{tabular}

outside of the past $24 \mathrm{~h}$ are not scored. The DSI yields two scores: the number of items endorsed (frequency) and an intensity measure (sum of scores divided by the frequency), with higher scores indicating higher perceived stress. The scale has good psychometric properties ${ }^{52}$ and has been validated against measures of autonomic responsiveness and somaticism ${ }^{53}$.

Affect Intensity Measure (AIM) ${ }^{54}$ is a 40 -item self-report questionnaire that quantifies the intensity with which an individual experiences emotion, irrespective of hedonic tone, on a 6-point scale (e.g., 'When I am nervous I get shaky all over,' 'When something good happens, I am usually much more jubilant than others'). The items were empirically derived from a larger set based on construct validity and have been validated against daily ratings of reactions to specific events. Stability in scores over a two year period has been documented ${ }^{55}$, indicating that the scale indexes a core trait of emotionality. The AIM is scored by averaging the responses across all items after reverse coding some. Higher values indicate higher affective intensity.

Spielberger State-Trait Anxiety Scales $(S T A I)^{56}$ are the most commonly used selfadministered measures of anxiety and have been extensively validated. Trait anxiety was assessed through 20 4-point items; higher scores indicate higher anxiety.

Center for Epidemiological Studies Depression Scale $(C E S-D)^{57}$ includes 20 depressive symptoms evaluated along 4 point (0-3) scales. It has been widely applied and has an extensive validity and reliability history.

\section{Data analysis}

Psychometric analysis of the PES proceeded as follows. First, descriptive analyses were performed on the individual items after combining the PES data collected from Cohort 1 at 30 weeks and Cohort 2 at 32 weeks. Although the last assessments in each cohort were also two weeks apart, we did not elect to perform the reliability analyses on these data because of attrition due to delivery in Cohort 2. Internal reliability was assessed using Cronbach's alpha. Trends over gestation for each PES score were assessed by repeated measures analysis of variance, with maternal parity as a betweensubjects factor. Test-retest stability was evaluated using Pearson correlations for each sample individually because of the different intervals of assessment. Concurrent validity was established for each cohort by correlating PES scores with other instruments measuring stress and affect (i.e., DSI, AIM, CESD, and STAI). Finally, exploratory principal components factor extraction with varimax rotation was conducted on the entire sample to determine the nature and number of underlying dimensions by examining individual item loadings.

\section{RESULTS}

\section{Item analysis}

Table 3 lists the top 10 items endorsed as either uplifts or hassles at the 30 and 32 week assessments. The most frequent uplift was 'How much the baby is moving' which was endorsed by $98 \%$ of participants. The most common hassle was 'Normal discomforts of pregnancy', endorsed by $91 \%$ of respondents. Uplift items were endorsed by a greater percentage of women than were hassles. The item least frequently endorsed as an uplift was 'Concerns about physical symptoms' and the item least considered to be a hassle was 'Spiritual feelings about being pregnant'. No item was endorsed as either a hassle or an uplift by less than $15 \%$ of the entire sample, our a priori rule for eliminating items from the scale. Internal reliability values were high: $\alpha=0.95$ for hassles and $\alpha=0.91$ for uplifts.

\section{Scale Scores: Hassles relative to uplifts and} gestational trends

Table 4 presents the mean values for the frequency and intensity scale scores. There are no missing data in Cohort 1 . Forty-six (33\%) participants in Cohort 2 did not 
Table 3 PES ten most frequently endorsed pregnancy uplifts and hassles $(n=189)$

\begin{tabular}{|c|c|c|c|}
\hline & $\%$ & M & $S D$ \\
\hline \multicolumn{4}{|l|}{ Uplifts } \\
\hline How much the baby is moving & 98 & 2.55 & 0.68 \\
\hline Visits to the obstetrician/midwife & 97 & 2.02 & 0.76 \\
\hline Thinking about the baby's appearance & 96 & 2.30 & 0.83 \\
\hline Feelings about being pregnant at this time & 96 & 2.28 & 0.82 \\
\hline Making or thinking about nursery arrangements & 93 & 2.07 & 0.88 \\
\hline Discussions with spouse about baby names & 91 & 1.95 & 0.95 \\
\hline Courtesy/assistance from others because you're pregnant & 91 & 1.89 & 0.94 \\
\hline Comments from others about your pregnancy/appearance & 91 & 1.75 & 0.89 \\
\hline Discussions with spouse about pregnancy/childbirth issues & 89 & 1.83 & 0.89 \\
\hline Spiritual feelings about being pregnant & 88 & 2.11 & 0.97 \\
\hline \multicolumn{4}{|l|}{ Hassles } \\
\hline Normal discomforts of pregnancy & 91 & 1.44 & 0.79 \\
\hline Ability to do tasks/chores & 88 & 1.46 & 0.80 \\
\hline Clothes/shoes don't fit & 88 & 1.36 & 0.76 \\
\hline Getting enough sleep & 85 & 1.59 & 0.96 \\
\hline Body changes due to pregnancy & 85 & 1.33 & 0.83 \\
\hline Your weight & 82 & 1.33 & 0.88 \\
\hline Thinking about your own labor and delivery & 80 & 1.23 & 0.83 \\
\hline Thoughts about whether the baby is normal & 76 & 1.24 & 0.93 \\
\hline Physical intimacy & 68 & 1.04 & 0.93 \\
\hline Concerns about physical symptoms & 66 & 1.12 & 0.92 \\
\hline
\end{tabular}

Table 4 Means and standard deviations of PES frequency and intensity scales

\begin{tabular}{|c|c|c|c|c|c|c|c|}
\hline & \multicolumn{3}{|c|}{ Cohort 1} & \multirow[b]{2}{*}{$F$} & \multicolumn{2}{|c|}{ Cohort 2} & \multirow[b]{2}{*}{$F$} \\
\hline & $\begin{array}{c}24 \text { weeks } \\
M \\
(S D)\end{array}$ & $\begin{array}{c}30 \text { weeks } \\
M \\
(S D)\end{array}$ & $\begin{array}{c}36 \text { weeks } \\
M \\
(S D)\end{array}$ & & $\begin{array}{c}32 \text { weeks } \\
M \\
(S D)\end{array}$ & $\begin{array}{c}38 \text { weeks } \\
M \\
(S D)\end{array}$ & \\
\hline \multicolumn{8}{|c|}{ Frequency Hassles } \\
\hline All & $\begin{array}{l}18.44 \\
(7.33)\end{array}$ & $\begin{array}{l}18.79 \\
(7.73)\end{array}$ & $\begin{array}{l}19.88 \\
(7.70)\end{array}$ & $2.28^{a}$ & $\begin{array}{l}19.55 \\
(6.20)\end{array}$ & $\begin{array}{l}18.95 \\
(6.36)\end{array}$ & $0.25^{a}$ \\
\hline Nulliparous & $\begin{array}{l}17.36 \\
(1.26)\end{array}$ & $\begin{array}{l}18.09 \\
(1.35)\end{array}$ & $\begin{array}{l}19.24 \\
(1.35)\end{array}$ & $1.20^{\mathrm{b}}$ & $\begin{array}{l}19.08 \\
(0.87)\end{array}$ & $\begin{array}{c}18.66 \\
(0.90)\end{array}$ & $0.13^{b}$ \\
\hline Multiparous & $\begin{array}{c}20.32 \\
(1.66)\end{array}$ & $\begin{array}{c}20.00 \\
(1.78)\end{array}$ & $\begin{array}{l}21.00 \\
(1.77)\end{array}$ & & $\begin{array}{l}19.33 \\
(0.94)\end{array}$ & $\begin{array}{l}19.23 \\
(0.99)\end{array}$ & \\
\hline \multicolumn{8}{|c|}{ Frequency Uplifts } \\
\hline All & $\begin{array}{c}27.50 \\
(7.33)\end{array}$ & $\begin{array}{l}28.46 \\
(6.65)\end{array}$ & $\begin{array}{l}28.40 \\
(7.65)\end{array}$ & 0.84 & $\begin{array}{l}28.31 \\
(6.51)\end{array}$ & $\begin{array}{c}28.99 \\
(6.92)\end{array}$ & 1.55 \\
\hline Nulliparous & $\begin{array}{c}26.46 \\
(1.27)\end{array}$ & $\begin{array}{c}28.73 \\
(1.17)\end{array}$ & $\begin{array}{c}29.36 \\
(1.33)\end{array}$ & 0.01 & $\begin{array}{c}29.62 \\
(0.87)\end{array}$ & $\begin{array}{c}29.52 \\
(0.98)\end{array}$ & 2.42 \\
\hline Multiparous & $\begin{array}{c}29.32 \\
(1.67)\end{array}$ & $\begin{array}{l}28.00 \\
(1.54)\end{array}$ & $\begin{array}{c}26.74 \\
(1.75)\end{array}$ & & $\begin{array}{c}26.83 \\
(0.95)\end{array}$ & $\begin{array}{c}28.36 \\
(1.07)\end{array}$ & \\
\hline \multicolumn{8}{|l|}{ Intensity Hassles } \\
\hline All & $\begin{array}{c}1.38 \\
(0.28)\end{array}$ & $\begin{array}{c}1.39 \\
(0.36)\end{array}$ & $\begin{array}{c}1.39 \\
(0.32)\end{array}$ & 0.09 & $\begin{array}{c}1.43 \\
(0.27)\end{array}$ & $\begin{array}{c}1.37 \\
(0.29)\end{array}$ & $4.90^{*}$ \\
\hline Nulliparous & $\begin{array}{c}1.38 \\
(0.05)\end{array}$ & $\begin{array}{c}1.43 \\
(0.06)\end{array}$ & $\begin{array}{c}1.38 \\
(0.06)\end{array}$ & 0.11 & $\begin{array}{c}1.39 \\
(0.39)\end{array}$ & $\begin{array}{c}1.35 \\
(0.41)\end{array}$ & 0.90 \\
\hline Multiparous & $\begin{array}{c}1.38 \\
(0.07)\end{array}$ & $\begin{array}{c}1.33 \\
(0.08)\end{array}$ & $\begin{array}{c}1.41 \\
(0.07)\end{array}$ & & $\begin{array}{c}1.46 \\
(0.04)\end{array}$ & $\begin{array}{c}1.39 \\
(0.04)\end{array}$ & \\
\hline \multicolumn{8}{|l|}{ Intensity Uplifts } \\
\hline All & $\begin{array}{c}1.95 \\
(0.40)\end{array}$ & $\begin{array}{c}1.91 \\
(0.41)\end{array}$ & $\begin{array}{c}1.86 \\
(0.42)\end{array}$ & 2.68 & $\begin{array}{c}1.91 \\
(0.41)\end{array}$ & $\begin{array}{c}1.93 \\
(0.41)\end{array}$ & 0.23 \\
\hline Nulliparous & $\begin{array}{c}1.95 \\
(0.07)\end{array}$ & $\begin{array}{c}1.95 \\
(0.07)\end{array}$ & $\begin{array}{c}1.92 \\
(0.07)\end{array}$ & 0.87 & $\begin{array}{c}2.02 \\
(0.05)\end{array}$ & $\begin{array}{c}2.05 \\
(0.05)\end{array}$ & $12.5 * *$ \\
\hline Multiparous & $\begin{array}{c}1.94 \\
(0.09)\end{array}$ & $\begin{array}{c}1.83 \\
(0.09)\end{array}$ & $\begin{array}{c}1.75 \\
(0.09)\end{array}$ & & $\begin{array}{c}1.78 \\
(0.06)\end{array}$ & $\begin{array}{c}1.77 \\
(0.06)\end{array}$ & \\
\hline
\end{tabular}

${ }^{*} p<0.05 .{ }^{* *} p<0.01$

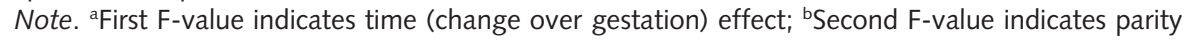
(nulliparous $v$ multiparous effect) 
complete the 38 week protocol because they delivered prior to their scheduled visit. There were no significant time trends in hassles or uplifts for Cohort 1 (i.e., from 24 to 36 weeks). Time effects for intensity were found in Cohort 2, with women reporting a small decrement in intensity of hassles from 32 to 38 weeks.

Repeated measures ANOVA comparing hassles to uplifts over time revealed consistent differences. Both cohorts nominated uplifts more frequently than hassles $(F$ $(1,51)=54.41 \quad$ and $F \quad(1,91)=152.88$, $p$ 's $<0.0001$, respectively), and felt uplifts with greater intensity $(F(1,51)=80.56$ and $F$ $(1,91)=157.22$, $p$ 's $<0.0001)$. Mean ratio scores were similar in both cohorts and are presented in Figure 1. On average, the magnitude of hassles was about $75 \%$ of uplifts, whether based on intensity or frequency. There were no changes over time in these measures, with the exception of lesser intensity of hassles relative to uplifts ( $F$ $(1,91)=4.37, p<0.05)$ from 32 to 38 weeks in Cohort 2.

Table 4 also presents data stratified by maternal parity. The only main effect for parity was a higher intensity of uplifts for nulliparous women in Cohort 2. There was a significant interaction between parity and time in Cohort 1. Nulliparous women reported an increasing number of uplifts with advancing gestation while multiparous women reported a decrease $(F(1,50)=5.71$, $p<0.01)$. There was a marginally significant interaction for frequency ratio scores ( $F$ $(1,50)=2.81, \quad p<0.10) \quad$ with decreasing (more uplifts relative to hassles) scores for nulliparous women and increasing values for multiparous women (more hassles relative to uplifts).

\section{Test-retest reliability}

Test-retest reliability correlations are presented in Table 5. Highly significant and consistent associations reveal that there is stability in both frequency and intensity of PES responses during this period of gestation.

\section{Relationship of hassles and uplifts}

Correlations within gestational age indicate consistently low, positive associations between hassles and uplifts. Women who reported greater frequency of hassles also reported more uplifts ( $r$ s range from 0.08 to 0.21 ), and there was a similar pattern of associations between intensity scores ( $r \mathrm{~s}$ range from 0.15 to 0.26 ). All associations were positive, but few attained significance $(p<0.05)$.

\section{Associations with other psychosocial} measures

Correlations between PES scores, DSI and AIM values are presented in Table 6. The

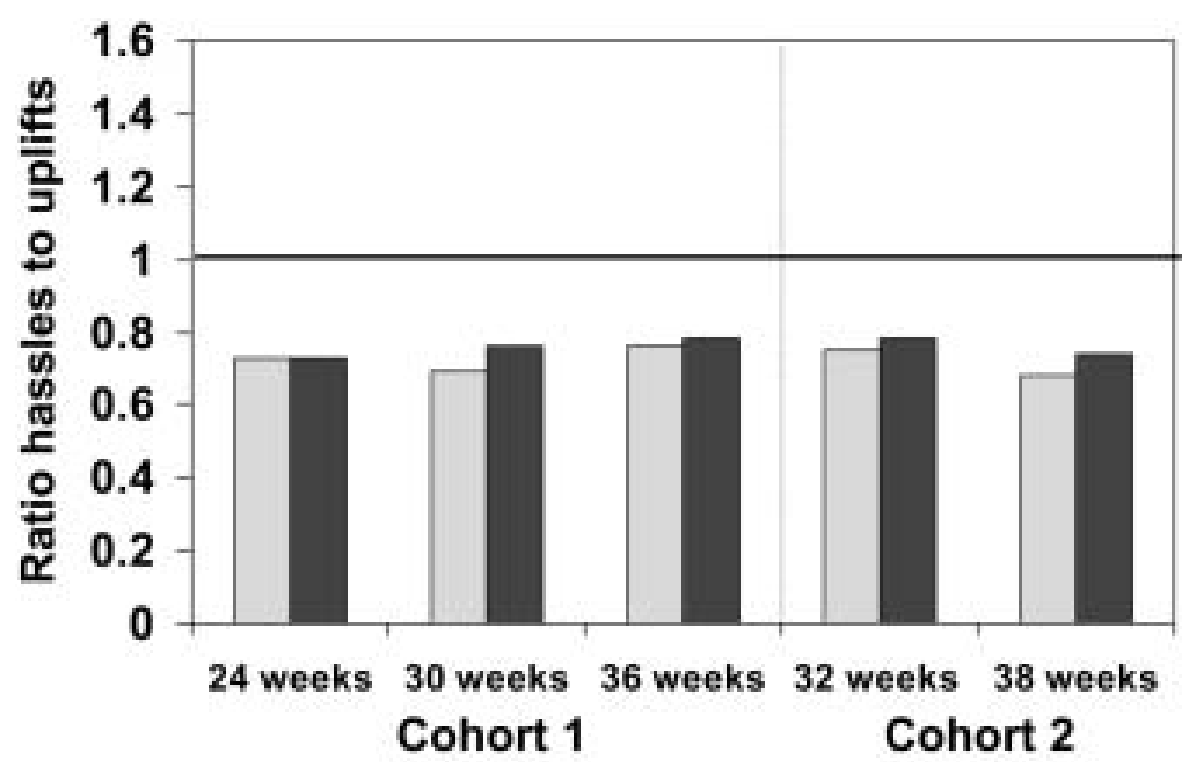

\section{Frequency Intensity}

Figure 1 Ratio frequency and intensity scores of pregnancy-specific hassles relative to uplifts. Values less than 1.0 indicate greater uplifts relative to hassles 
Table 5 Test-retest reliability: Correlations over time

\begin{tabular}{lccccc}
\hline & \multicolumn{3}{c}{ Cohort 1 $(\mathrm{n}=52)$} & & Cohort 2 $\left(\mathrm{n}=92^{\mathrm{a}}\right)$ \\
\cline { 2 - 3 } Gestational ages (weeks) & 24 to 30 & 30 to 36 & 24 to 36 & & 32 to 38 \\
\hline Hassles Frequency & 0.79 & 0.83 & 0.70 & 0.70 \\
Uplifts Frequency & 0.62 & 0.79 & 0.57 & 0.72 \\
Hassles Intensity & 0.72 & 0.67 & 0.61 & \\
Uplifts Intensity & 0.78 & 0.80 & 0.69 & \\
Frequency Ratio & 0.66 & 0.66 & 0.67 & 0.66 \\
Intensity Ratio & 0.63 & 0.57 & 0.66 & \\
\hline
\end{tabular}

Note. All $p s<0.0001$

${ }^{a} n$ reflects attrition due to delivery by 38 weeks

Table 6 Concurrent validity: Correlations between PES, DSI, and AIM scores

\begin{tabular}{|c|c|c|c|c|c|c|c|c|}
\hline & \multicolumn{6}{|c|}{ Cohort 1} & \multirow{2}{*}{\multicolumn{2}{|c|}{$\frac{\text { Cohort } 2}{38^{a}}$}} \\
\hline & \multicolumn{2}{|c|}{24} & \multicolumn{2}{|c|}{30} & \multicolumn{2}{|c|}{36} & & \\
\hline & $D S I$ & AIM & $D S I$ & AIM & $D S I$ & AIM & $D S I$ & AIM \\
\hline Frequency Hassles & 0.09 & $-0.25^{*}$ & 0.03 & -0.10 & -0.04 & -0.02 & $0.28^{* *}$ & -0.10 \\
\hline Frequency Uplifts & $-0.26^{*}$ & 0.13 & -0.01 & $0.27^{*}$ & -0.17 & 0.17 & -0.03 & -0.04 \\
\hline Intensity Hassles & $0.25^{*}$ & $0.25^{*}$ & $0.35^{*}$ & $0.25^{*}$ & $0.27^{*}$ & 0.04 & $0.30 * *$ & $0.27^{* *}$ \\
\hline Intensity Uplifts & $-0.25^{*}$ & $0.43^{* *}$ & -0.08 & $0.32 *$ & -0.14 & 0.01 & $-0.26^{* *}$ & $0.22 *$ \\
\hline Frequency Ratio & $0.24^{*}$ & -0.22 & 0.09 & $-0.26^{*}$ & 0.20 & -0.18 & $0.24^{*}$ & -0.07 \\
\hline Intensity Ratio & $0.38 * *$ & -0.16 & $0.36^{* *}$ & -0.02 & $0.35^{* *}$ & -0.04 & $0.44 * * *$ & 0.02 \\
\hline
\end{tabular}

${ }^{*} p<0.05 .{ }^{*} p<0.01 .{ }^{* *} p<0.001$. Based on one-tailed test

${ }^{a}$ Correlations with DSI/AIM at 36 weeks

most consistent pattern of correlations emerged with PES intensity, as compared to frequency, scales. Hassles intensity and intensity ratio scores were significantly and positively related to non-specific stress scores (DSI) at each gestational age and in both samples, with somewhat higher correlations for the latter. Intensity of both hassles and uplifts was associated with affective intensity scores, except at 36 weeks. Uplift intensity was negatively associated with DSI scores, although the associations were not consistently significant.

For Cohort 2, measures used in analyses with the PES were those collected within adjacent visits, separated by 4 weeks. Validity of the PES was also assessed with depression and anxiety scales. CESD and STAI scores were significantly related to hassles frequency ( $r$ 's $=0.40$ and 0.39 , respectively), intensity ( $r$ 's $=0.41$ and 0.34 ) and both frequency ( $r$ 's $=0.33$ and 0.36 ) and intensity $(r$ 's $=0.37$ and 0.34$)$ ratios. The CESD and STAI were unrelated to uplifts intensity or frequency ( $r$ 's range from -0.11 to -0.08 ).

A final consideration is the degree to which women regard PES items as relevant compared to items on other psychosocial measures. The percent of pregnancy-specific items appraised as hassles was higher than non-specific items nominated from the DSI in both cohorts. In Cohort 1, between 45 and $49 \%$ of PES items were nominated as hassles compared to 37 and $38 \%$ of DSI daily stress items. Comparable numbers for Cohort 2 were 46 to $48 \%$ PES endorsements vs. 32 to $34 \%$ DSI items.

\section{Factor analysis}

The principal components analysis was conducted on combined PES uplifts scores of Cohort 1 (30 weeks) and Cohort 2 (32 weeks). Initial extraction yielded 11 factors. Six factors contained few highly loading items and limited variance; forced extraction of 5 factors yielded a final model accounting for $52 \%$ of the variance. No items on this solution had low loadings $(<0.40)$. Content analysis suggested the following underlying factor constructs: (1) Psychological and physical preparation for baby (PES items 4, $5,8,9,10,25,26,37$ ); (2) Changes in lifestyle of self and spouse (items 6, 7, 13, 14, 19, 22, 32, 33, 38); (3) Relationships with family and friends (items 16, 17, 18, 20, 23, 
24, 28, 29, 39, 21); (4) Pregnancy concerns and occurrences (items 11, 15, 27, 31, 34, 35, 36, 40, 41); and (5) Body image and self (items 1, 2, 3, 12, 30).

A factor analysis was also performed for the hassles items and yielded an 8 factor solution in which rotation failed to converge after 25 iterations. A forced five factor solution accounted for $60 \%$ of the variance. The underlying construct structure for these factors was similar to that determined for uplifts, with some variation in where specific items loaded most highly.

\section{DISCUSSION}

The Pregnancy Experience Scale (PES) appears to be a valid, reliable tool for capturing positive perceptions of pregnancy as well as pregnancy-specific hassles. The intensity of pregnancy-specific hassles was positively correlated with the intensity with which women perceived daily life in general to be stressful. Uplifts tended to be inversely related to non-pregnancy specific stress appraisal, but the results were not uniform across gestation. The intensity with which women perceive their pregnancy to be hassling relative to uplifting provided the most consistent associations with the measure of non-pregnancy specific stress. This ratio measure is also most strongly related to the degree of motor activity generated by the fetus ${ }^{2}$, suggesting that measurement of negative perceptions of pregnancy relative to positive ones may provide the best indicator of pregnancy-specific distress.

There was a high degree of test-retest stability in frequency, intensity, and ratio scores over time (12 weeks in Cohort 1 and 6 weeks in Cohort 2). This is consistent with results generated by non-pregnancy specific hassles scales, including a sample of nonpregnant women with young children ${ }^{40}$, suggesting that either women are exposed to consistent sources of stress or that such scales may also be reflecting dispositional attributes. Support for the latter is provided from two sources. First, general affective intensity, as measured by the AIM, was significantly associated with both hassle and uplift intensity at three of the four gestational ages assessed. Second, there were significant positive relations between depressive symptoms and trait anxiety and all PES hassles and ratio measures. However, based on the strongest correlation with an individual PES score, the AIM, DSI, CESD, and STAI scales shared no more than $18,19,17$, and $15 \%$ of the variance, respectively, thereby establishing both convergent and discriminant validity for the PES.

The data generated by the uplifts portion of the scale are unique. Investigation into the manner in which women perceive pregnancy as an uplifting force in their lives is consistent with the recent impetus towards 'positive psychology', or the understanding of how psychological and physical well-being is fostered ${ }^{49}$. Although it is tempting to simply consider uplifts as the inverse of hassles, the current data indicate that this is not the case. Women who report more frequent or more intense pregnancy hassles also tend to report more uplifts. Moreover, uplifts were unrelated, not inversely related, to depressive symptoms and trait anxiety. Although the field of positive psychology is emergent, it is clear that positive emotions or moods are not simply the absence of negative states but are distinct constructs ${ }^{47}$ that operate in parallel but distinct biological systems ${ }^{58}$. The mechanisms through which uplifted feelings about pregnancy might physiologically transduce to fetal or gestational outcomes are unknown. Maternal anxiety has been associated with reduced blood flow to the fetus $^{59,60}$. Neuroendocrines of the hypothalamic-pituitary-adrenal axis have been implicated in associations between psychological stress and negative pregnancy outcomes $^{61}$. Comparable understanding of how positive emotions affect physiological processes in general, and pregnancy in particular, does not exist at this time. However, two positive emotions, joy and contentment, have been shown to hasten recovery from cardiovascular reactivity that is associated with stress in non-pregnant subjects ${ }^{48}$. Such findings raise the possibility that feelings of uplift and elevation during pregnancy may alleviate vasoconstrictive influences on the intrauterine environment.

Each of the factors that emerged from the principal components analysis are reflected, in part, by the nature of the 20 most frequently endorsed items. The content structure of the factors are similar to that generated by other measures of pregnancyspecific stress ${ }^{13,34-36,62}$. These include changes in body image, somatic symptoms, concerns about delivery and the baby's well-being, and changes in social relationships and status among partners, family, and friends intimate relationships with partners. An additional set 
of issues regarding effects of pregnancy and a new baby on other children was identified for multiparous women.

A limitation of this study in understanding the natural course of pregnancy-specific stress is its initiation mid-way through pregnancy. Other studies that have included non-pregnancy hassles report either an increase in hassles frequency but a decrease in intensity from first through third trimesters $^{44}$, higher hassles and pregnancyspecific stress in the first trimester than in either the second or third ${ }^{9}$, or no change ${ }^{62}$. We detected few changes in pregnancyspecific hassles and uplifts, supporting the latter report. However, comparability across reports is limited by variation in the gestational ages studied, and the current study is least likely to detect changes because we did not collect data prior to 24 weeks gestation.

Although the research literature has focused on the stressful nature of pregnancy, the results of this study suggest that focusing on the negative aspects of pregnancy may miss the positive psychological consequences. Because women systematically perceived pregnancy as more uplifting than hassling during the second half of gestation, we believe that the literature may paint a biased view of pregnancy distress. Both of the current cohorts were comprised of a large proportion of professional, working women with multiple time and role demands, including other children. Nulliparous women tended to be more uplifted about the pregnancy, particularly as term approached, than did multiparous women, reflecting either fewer competing demands or greater anticipation of impending motherhood.

In contrast to the population of welleducated, relatively advantaged women with mostly planned and wanted pregnancies in this study, most studies of pregnancy have evaluated stress in socioeconomically disadvantaged samples. The question arises as to whether our results reflecting the positive emotional valence surrounding pregnancy are generalizable to women in different circumstances. This is a difficult question to answer because of the limited degree of data collected about positive pregnancy experiences in women of lower socioeconomic status, in part because of the lack of adequate research tools. In a report based on a sample of 50 impoverished, poorly educated women eligible for free prenatal care services, we found similar patterns of endorsement of the most frequent hassles and uplifts items. When compared to Cohort 1 in the current report, women in the low socioeconomic group reported significantly fewer pregnancy specific hassles and significantly more uplifts from 24 to 36 weeks gestation ${ }^{63}$. Additional research incorporating data collection on both positive and negative appraisal of pregnancy in samples of low income women, as well as attention to potential determinants including social support, economic sufficiency, and pregnancy wantedness are required before conclusions regarding generalizability or lack thereof can be made.

Pregnancy is a time of enormous adaptive psychological demands but also represents a period of fulfillment for many women. Restricting measurement of stress during pregnancy to non-pregnant specific events or appraisal will invariably under-represent the degree to which women experience stress during pregnancy. However, measuring pregnancy specific distress without also measuring positive emotional responses to pregnancy may overestimate distress and fail to accurately depict the degree to which women are psychologically elevated by their pregnancies. Complete ascertainment of pregnancy specific stress should include both positive and negative appraisal of the pregnancy experience.

\section{ACKNOWLEDGEMENTS}

This research was supported by the National Institutes of Health (R01 HD27592) awarded to the first author. Portions of the Cohort 1 data were presented at the New York Academy of Sciences conference 'Socioeconomic Status and Health in Industrial Nations: Social, Psychological and Biological Pathways', National Institutes of Health, Bethesda, MD, USA, May 1999. We thank Sarah Millet for her work on this project and our study families for their participation, without which this research would not have been possible.

\section{REFERENCES}

1. DiPietro JA, Hodgson DM, Costigan KA, et al. Fetal neurobehavioral development. Child Dev 1996;67:2553-67

2. DiPietro J, Hilton S, Hawkins M, et al. Maternal stress and affect influence fetal neurobehavioral development. Dev Psychol 2002;38:659-68 
3. Van den Bergh BRH, Mulder EJH, Visser GHA, et al. The effect of (induced) maternal emotions on fetal behaviour: A controlled study. Early Hum Dev 1989;19:9-19

4. Groome LJ, Swiber MJ, Bentz LS, et al. Maternal anxiety during pregnancy: Effect on fetal behavior at 38 and 40 weeks of gestation. J Dev Behav Pediatr 1995;16:391-96

5. Sjostrom K, Valentin 1, Thelin T, Marsal K. Maternal anxiety in late pregnancy: Effect on fetal movements and fetal heart rate. Early Hum Dev 2002;67:87-100

6. Sandman C, Wadhwa P, Chicz-DeMet A, et al. Maternal corticotropin-releasing hormone and habituation in the human fetus. Dev Psychobiol 1999;34:163-73

7. Neugebauer R, Kline J, Stein Z, et al. Association of stressful life events with chromosomally normal spontaneous abortion. Am J Epidemiol 1996;143:588-96

8. Schaefer C, Hiatt RA, Swan S, Windham G. Psychosocial stress and spontaneous abortion. Ann Behav Med 1997;19S:70

9. DaCosta D, Brender W, Larouche J. A prospective study of the impact of psychosocial and lifestyle variables on pregnancy complications. J Psychosom Obstet Gynecol 1998;19:28-37

10. Copper RL, Goldenberg RL, Das A, et al. The preterm prediction study: Maternal stress is associated with spontaneous preterm birth at less than thirty-five weeks' gestation. Am J Obstet Gynecol 1996;175:1286-92

11. Hedegaard M, Henriksen TB, Secher NJ, et al. Do stressful life events affect duration of gestation and risk of preterm delivery? Epidemiology 1996;7:339-45

12. Lobel M, Dunkel-Schetter C, Scrimshaw SCM. Prenatal maternal stress and prematurity: A prospective study of socioeconomically disadvantaged women. Health Psychol 1992:11:32-40

13. Mamelle N, Measson A, Munoz F, et al. Development and use of a self-administered questionnaire for assessment of psychological attitudes toward pregnancy and their relation to a subsequent premature birth. Am J Epidemiol 1989;130(5):989-98

14. Mutale T, Creed F, Maresh M, Hunt L. Life events and low birth weight analysis by infants preterm and small for gestational age. $\mathrm{Br} J$ Obstet Gynaecol 1991;122:47-59

15. Nordentoft M, Lou HC, Hansen D, et al. Intrauterine growth retardation and premature delivery: The influence of maternal smoking and psychosocial factors. Am J Public Health 1996;86:347-54

16. Orr ST, James SA, Miller CA, et al. Psychological stressors and low birthweight in an urban population. Am J Prev Med 1996;12:459-66

17. Wadhwa PD, Sandman CA, Porto M, et al. The association between prenatal stress and infant birth weight and gestational age at birth: A prospective investigation. Am J Obstet Gynecol 1993;169:858-65
18. Austin M, Leader L. Maternal stress and obstetric and infant outcomes: epidemiological findings and neuroendocrine mechanisms. Aust NZ J Obstet Gynaecol 2000;40:331-37

19. Istvan J. Stress, anxiety, and birth outcomes: A critical review of the evidence. Psychol Bull 1986;100:331-48

20. Paarlberg KM, Vingerhoets A, Passchier J, et al. Psychosocial factors and pregnancy outcome: A review with emphasis on methodological issues. J Psychosom Res 1995;39:563-95

21. Wadhwa PD. Prenatal stress and life-span development. In: Friedman HS, ed. Encyclopedia of Mental Health. San Diego: Academic Press; 1998:265-80

22. Clarke AS, Wittwer DJ, Abbott DH, Schneider ML. Long-term effects of prenatal stress on HPA axis activity in juvenile rhesus monkeys. Dev Psychobiol 1994;27:257-69

23. Huizink A, deMedina P, Mulder E, et al. . Psychological measures of prenatal stress as predictors of infant temperament. J Am Acad Child Adolesc Psychiatry 2002;41:1078-85

24. Kofman $\mathrm{O}$. The role of prenatal stress in the etiology of developmental behavioral disorders. Neurosci Biobehav Rev 2002;26:45770

25. Mulder E, RoblesdeMedina P, Huizink A, et al. Prenatal maternal stress: Effects on pregnancy and the (unborn) child. Early Hum Dev 2002;70:3-14

26. Schneider M, Moore C. Effects of prenatal stress on development: A non-human primate model. In: Nelson C, ed. The effects of early adversity on neurobehavioral development. Mahwah, NJ: Lawrence Erlbaum Associates; 2000:201-44

27. Weinstock M. Alterations induced by gestational stress in brain morphology and behavior of the offspring. Prog Neurobiol 2001;65:427-51

28. Welberg L, Seckl J. Prenatal stress, glucocorticoids and the programming of the brain. J Neuroendocrinol 2001;13:113-28

29. Lobel M. Conceptualizations, measurement, and effects of prenatal maternal stress on birth outcomes. J Behav Med 1994;17:225-72

30. McLean DE, Hatfield-Timajchy K, Wingo PA, Floyd RL. Psychosocial measurement: Implications for the study of preterm delivery in black women. Am J Prev Med 1993;9(6 Supplement):39-81

31. Carlson D, LaBarba R. Maternal emotionality during pregnancy and reproductive outcome: A review of the literature. Int J Behav Dev 1979;2:343-76

32. Holmes TH, Rahe RH. The social readjustment rating scale. J Psychosom Res 1967;11:213-18

33. Zajicek E, Wolkind S. Emotional difficulties in married women during and after the first pregnancy. Br J Med Psychol 1978;51:379-85

34. Arizmendi T, Affonso D. Stressful events related to pregnancy and postpartum. J Psychosom Res 1987;31:743-56 
35. Kumar R, Robson KM, Smith AMR. Development of a self-administered questionnaire to measure maternal adjustment and maternal attitudes during pregnancy and after delivery. J Psychosom Res 1984;28:43-51

36. Yali A, Lobel M. Coping and distress in pregnancy: An investigation of medically high risk women. J Psychosom Obstet Gynecol 1999;20:39-52

37. Curry M, Burton D, Fields J. The Prenatal Psychological Profile: A research and clinical tool. Res Nurs Health 1998;21:211-19

38. Orr ST, James SA, Casper R. Psychosocial stressors and low birth weight: Development of a questionnaire. J Dev Behav Pediatr 1992;13:343-47

39. Levin J. The factor structure of the Pregnancy Anxiety Scale. J Health Soc Behav 1991;32:36881

40. Chamberlain K, Zika S. The minor events approach to stress: Support for the use of daily hassles. Br J Psychol 1990;81:469-81

41. DeLongis A, Folkman S, Lazarus RS. The impact of daily stress on health and mood: Psychological and social resources as mediators. J Pers Soc Psychol 1988;54:486-95

42. Curry MA, Campbell RA, Christian M. Validity and reliability testing of the prenatal psychosocial profile. Res Nurs Health 1994;17:127-35

43. Mackey M, Williams C, Tiller C. Stress, preterm labour and birth outcomes. J Adv Nurs 2000;32:666-74

44. Thompson L, Murphy P, O’Hara J, Wallymahmed A. Levels of daily hassles and uplifts in employed and non-employed pregnant women. J Reprod Infant Psychol 1997:271-80

45. Ayers S. Assessing stress and coping in pregnancy and the postpartum. J Psychosom Obstet Gynecol 2001;22:12-27

46. Ruiz R, Fullerton J. The measurement of stress in pregnancy. Nurs Health Sci 1999;1:19-25

47. Diener E. Subjective well-being: The science of happiness and a proposal for a national index. Am Psychol 2000;55:34-43

48. Fredrickson B. The role of positive emotions in positive psychology: The broaden-and-build theory of positive emotions. Am Psychol 2001;56:281-26

49. Seligman M. Positive psychology. In: Gilham J, ed. The Science of Optimism and Hope. Philadelphia, PA: Templeton Foundation Press; 2000:415-29
50. Lobel M, DeVincent C, Kaminer A, Meyer B. The impact of prenatal maternal stress and optimistic disposition on birth outcomes in medically high-risk women. Health Psychol 2000;19:544-53

51. Diener E, Larsen RJ, Levine S, Emmons RA. Intensity and frequency: Dimensions underlying positive and negative affect. J Pers Soc Psychol 1985;48:1253-65

52. Brantley PJ, Waggoner CD, Jones GN, Rappaport NB. A daily stress inventory: Development, reliability, and validity. J Behav Med 1987;10:61-73

53. Waters WF, Rubman S, Hurry MJ. The prediction of somatic complaints using the Autonomic Nervous System Response Inventory and the Daily Stress Inventory. $J$ Psychosom Res 1993;37:117-26

54. Larsen RJ, Diener E, Emmons RA. Affect intensity and reactions to daily life events. J Pers Soc Psychol 1986;51:803-14

55. Larsen RJ, Diener E. Affect intensity as an individual difference characteristic: A review. J Res Pers 1987;21:1-39

56. Spielberger C. Manual for the State-Trait Anxiety Inventory (Form Y). Palo Alto, CA: Mind Garden, Inc, 1983

57. Radloff LS. The CES-D scale: A self-report depression scale for research in the general population. Appl Psychol Meas 1977;1:385-401

58. Cacioppo J, Gardner W, Berntson G. The affect system has parallel and integrative processing components. J Pers Soc Psychol 1999;76:839-55

59. Sjostrom K, Valentin L, Thelin T, Marsal K. Maternal anxiety in late pregnancy and fetal hemodynamics. Eur J Obstet Gynecol 1997;74:149-55

60. Teixeira JM, Fisk NM, Glover V. Association between maternal anxiety in pregnancy and increased uterine artery resistance index: Cohort based study. Br Med J 1999;318:153-57

61. Wadhwa PD, Sandman CA, Chicz-DeMet A, Porto M. Placental CRH modulates maternal pituitary-adrenal function in human pregnancy. Ann NY Acad Sci 1997;814:276-81

62. DaCosta D, Larouche J, Dritsa M, Brender W. Variations in stress levels over the course of pregnancy: Factors associated with elevated hassles, state anxiety and pregnancy-specific stress. J Psychosom Res 1999;47:609-21

63. Hawkins M, DiPietro J, Costigan K. Social class differences in maternal stress appraisal during pregnancy. Ann NY Acad Sci 1999;896:439-41. 


\section{APPENDIX}

\section{The Pregnancy Experience Scale}

Below is a list of things you may experience during pregnancy that may affect you in a variety of ways. They may make you feel happy, positive, uplifted or they make you feel unhappy, negative, or upset, or some of each. Please respond to each item. Make sure that you circle a number on both sides of each question.

\section{$0=$ not at all \\ $1=$ somewhat \\ 2 = quite $a$ bit \\ $3=\mathrm{a}$ great deal \\ How much has this \\ made you feel happy, \\ positive or uplifted?}

$0=$ not at all

$1=$ somewhat

2 = quite $a$ bit

$3=a$ great deal

How much has this

made you feel unhappy, negative, or upset?
0123

0123

0123

0123

0123

0123

0123

0123

0123

0123

0123

0123

0123

0123

0123

0123

0123

0123

0123

0123

0123

0123

0123

0123

0123

0123

0123

0123

0123

0123

0123

0123

0123

0123

0123

0123

0123

0123

0123

0123

0123
1. Clothes/shoes don't fit

0123

0123

0123

0123

0123

0123

0123

0123

0123

0123

0123

0123

0123

0123

0123

0123

0123

0123

0123

0123

0123

0123

0123

0123

0123

0123

0123

0123

0123

0123

0123

0123

0123

0123

0123

0123

0123

0123

0123

0123

0123 


\section{Current knowledge on this subject}

- Psychological stress during pregnancy has been associated with a range of negative birth outcomes

- Measurement of stress during pregnancy is complicated by a variety of methodological issues

- Little attention has been devoted to quantifying the positive psychological aspects of pregnancy

\section{What this study adds}

- A new reliable, valid instrument to measures both negative and positive appraisal of pregnancy

- Support for the notion that failure to measure pregnancyspecific stress may underestimate the degree to which women experience distress during pregnancy

- In low risk women, pregnancy is regarded as consistently more uplifting than hassling 
Copyright of Journal of Psychosomatic Obstetrics \& Gynecology is the property of CRC Press LLC and its content may not be copied or emailed to multiple sites or posted to a listserv without the copyright holder's express written permission. However, users may print, download, or email articles for individual use. 